\title{
Corporate response strategies to regulatory uncertainty Evidence from uncertainty about post-Kyoto regulation
}

\author{
Journal Article \\ Author(s): \\ Engau, Christian; Hoffmann Volker H. \\ Publication date: \\ 2011-03 \\ Permanent link: \\ https://doi.org/10.3929/ethz-b-000027155 \\ Rights / license: \\ In Copyright - Non-Commercial Use Permitted \\ Originally published in: \\ Policy Sciences 44(1), https://doi.org/10.1007/s11077-010-9116-0
}




\title{
Corporate response strategies to regulatory uncertainty: evidence from uncertainty about post-Kyoto regulation
}

\author{
Christian Engau • Volker H. Hoffmann
}

Published online: 6 June 2010

(C) Springer Science+Business Media, LLC. 2010

\begin{abstract}
A better understanding of firms' response strategies to regulatory uncertainty enables policymakers to improve policymaking efficiency and to enhance the effectiveness of regulation. Based on a literature review, we categorize responses according to their objective toward regulatory uncertainty into four strategies: avoidance, reduction, adaptation, and disregard strategies. Unique data from a worldwide cross-industry survey show that firms predominantly pursue reduction, and to a lesser extent adaptation and disregard strategies, in response to post-Kyoto regulatory uncertainty. Surprisingly, firms in fact only sporadically pursue avoidance strategies, in contradiction to their own public announcements commonly made during policymaking to realize such strategies. The degree of regulatory uncertainty perceived and its interpretation as a threat increase the pursuit of most of these strategies. In addition, firms' response strategies to post-Kyoto regulatory uncertainty differ across industries and partly across regions.
\end{abstract}

Keywords Environmental policy $\cdot$ Post-Kyoto $\cdot$ Regulatory uncertainty · Corporate strategy $\cdot$ Climate change

\section{Introduction}

Over the past decades, governments around the world have considerably expanded global regulatory interventions in private economic activities. In today's globalized markets, economic relationships are increasingly integrated across national borders and are governed by a growing number of international regulations (Rugman and Verbeke 2001). An important objective of such regulations is to correct negative externalities and market failures (Crew 1982), generally through deliberately interfering with the behavior of market actors, especially firms (Rivera et al. 2009; Yarbrough and Yarbrough 1990). Because it is typically difficult for such firms to predict regulatory interferences (e.g.,

C. Engau $\cdot$ V. H. Hoffmann $(\bowtie)$

Department of Management, Technology, and Economics, ETH Zurich, Kreuzplatz 5, 8032 Zurich, Switzerland

e-mail: vhoffmann@ethz.ch 
Delmas and Tokat 2005; Hrebiniak and Snow 1980; Marcus 1981), they are exposed to considerable uncertainty. In this paper, we use the term 'regulatory uncertainty' to refer to uncertainty associated with the actions of governmental agencies that create and enforce regulations (Birnbaum 1984) and define it as a firm's "inability to predict the future state of the regulatory environment" (Hoffmann et al. 2008, p. 714).

Most studies in the abundant literature on firm behavior under uncertainty focus on one specific response strategy to a number of uncertainties in a firm's business environment, thereby often limiting the context to one individual industry and region (e.g., Dreyer and Grønhaug 2004; Elenkov 1997; Henisz and Delios 2001; Krickx 2000; Yang et al. 2004). However, research in the converse setting, i.e., the investigation of the full range of possible response strategies to one particular type of uncertainty across several industries and regions, remains limited. This is surprising as such an investigation could facilitate a comparative analysis for better understanding the determinants of firms' strategic responses to specific uncertainties (Hrebiniak and Snow 1980). Moreover, the particular field of response strategies to regulatory uncertainty has remained largely unexplored in spite of important differences that distinguish regulatory uncertainty from other uncertainties, such as its dependence on political negotiation, its discrete scenario character, and its discontinuous resolution (Doh and Pearce 2004; Engau and Hoffmann 2009). To address firms' response strategies to regulatory uncertainty, this paper identifies individual responses from the literature and categorizes them based on the specific objective toward uncertainty each is directed at, i.e., avoiding, reducing, adapting to, or disregarding uncertainty for decision making. The paper then investigates to what extent the degree of regulatory uncertainty and the interpretation of this uncertainty as a threat, i.e., firms' perceived controllability of its source and effect (Jackson and Dutton 1988), influence firms' response strategy pursuit to achieve these objectives.

Enhancing the understanding of firms' response strategies to regulatory uncertainty is crucial for practical policymaking and helps policymakers to address the challenge of predicting firms' behavior in face of such uncertainty. On the one hand, regulatory uncertainty might cause firms to implement anticipatory compliance measures that go beyond the regulatory requirements actually established later by policymakers. This is especially relevant in the case of flexible regulations that do not require firms to behave in a specific way, as command and control regulations do for example (Andrews 1998; Darnall and Carmin 2005), but provide considerable managerial discretion for pursuing individually developed response strategies (Kolk and Pinkse 2005; Majumdar and Marcus 2001). While this discretion can partially reduce regulatory uncertainty for firms, it makes it more difficult for policymakers to anticipate firms' behavior in formulating effective regulation. For example, Kolk and Pinkse study business responses to climate change in the uncertain regulatory environment that accompanies the post-Kyoto Protocol negotiations and identify various strategic profiles that firms adopt to address global warming, each applying a different combination of options to reduce and compensate for own $\mathrm{CO}_{2}$ emissions (Kolk and Pinkse 2005). Such deviating preferences for reduction or compensation measures can affect the effectiveness of flexible climate change regulation, for instance by mitigating incentives to actually reduce $\mathrm{CO}_{2}$ emissions, and policymakers should be aware of firms' behavior for example for the allocation of free emission allowances (Burtraw and Palmer 2008). Correspondingly, likely variations in firms' preferred responses across different industries (Hoffmann and Trautmann 2006; Hrebiniak and Snow 1980) and the possible influence of regional characteristics (Barr and Glynn 2004; Klassen and Angell 1998) can further complicate policy formulation at a global level. 
On the other hand, regulatory uncertainty considerably constrains firms and can adversely affect their profitability (Bourgeois 1985) because the continuous preparation for, and the adjustment to, uncertain regulations absorb firm resources (Cyert and March 1963; Koberg 1987). Correspondingly, anecdotal evidence suggests that regulatory uncertainty can keep firms from more effectively deploying these resources toward both their own commercial and policymakers' regulatory objectives (e.g., Brewer 2005; Hoffmann 2007; Levy 1997; Paulsson and von Malmborg 2004). In consequence, an insufficient understanding of firms' response strategies to regulatory uncertainty impedes efficient policymaking and makes it difficult for policymakers to design regulation that effectively fulfills its intended purpose (Arentsen et al. 2000).

Our research contributes to the understanding of firms' response strategies to regulatory uncertainty in three ways. First, we systematically analyze which responses to regulatory uncertainty are generally available to firms. To this end, we review the relevant literature and group the identified responses based on their objective toward regulatory uncertainty. Secondly, we examine criteria on which a firm's response strategy pursuit depends. In particular, we derive hypotheses as to how the degree of regulatory uncertainty perceived by firms and the perception of this uncertainty as a threat influence the pursuit of response strategies. Finally, focusing on global climate change regulation as specific research context, we test these hypotheses with unique data from a worldwide survey of corporate response strategies to the uncertainty associated with a successor scheme to the Kyoto Protocol. Based on this data, we provide insights into the actual behavior of firms in different industries and regions under post-Kyoto regulatory uncertainty.

\section{Theoretical background and hypotheses}

\section{Response strategies to regulatory uncertainty}

Research on strategy under uncertainty typically addresses two main fields, financial risk management techniques and strategic management responses (Miller 1992). While the former are mostly addressed in the economics literature that typically focuses on investment decisions and real options (e.g., Dixit 1989; Dixit and Pindyck 1994; Miller and Folta 2002), our analysis of corporate response strategies to regulatory uncertainty focuses on the latter.

Building on long-established categories in the organization theory literature, we posit that in principle firms pursue four objectives when responding to regulatory uncertainty, seeking to either avoid, reduce, adapt to, or disregard this uncertainty. Foremost, a core premise put forward by behavioral theorists is that firms seek to avoid uncertainty (Cyert and March 1963). Accordingly, in this paper, we categorize firms' responses to entirely prevent being exposed to regulatory uncertainty during decision making into an avoidance strategy. Moreover, Daft and Weick's concept of organizations as interpretation systems suggests that firms attempt to explore an environment to enhance their understanding of changing conditions and thus to reduce uncertainty (Daft and Weick 1984). Corresponding responses that directly target the regulatory uncertainty itself and seek to decrease it will be viewed as a reduction strategy. In addition, Hickson and colleagues categorize firms' behavior in uncertain environments from a contingency theory perspective and suggest that firms can pursue adaptation responses that attempt to minimize negative effects from the uncertainty that can neither be avoided nor be reduced (Hickson et al. 1971). In line with this notion, responses that aim at adjusting a firm's internal capacity to better cope with 
regulatory uncertainty without countering the uncertainty directly will be defined as an adaptation strategy.

Finally, rather than coping with the regulatory uncertainty they are exposed to by means of the three above-mentioned response strategies, it is also conceivable that firms choose to only make business decisions that do not require the consideration of uncertainty. Hence, our analysis complements the strategy types commonly found in the literature with a disregard strategy, under which we subsume responses that allow firms to ignore the regulatory uncertainty they are exposed to for their decision making. In contrast to firms pursuing avoidance or reduction strategies, those enacting a disregard strategy are still exposed to uncertainty to its full extent. Other than firms adapting to uncertainty, they do also not specifically prepare for better coping with regulatory uncertainty, but deliberately opt for at least temporarily disregarding this uncertainty and its effects.

Firms can enact each of these response strategies by means of a variety of different individual approaches (Table 1). The subsequent sections identify such approaches in the management literature and group them according to their primary objective toward regulatory uncertainty.

First, entrepreneurship theory suggests that firms' unwillingness to be exposed to uncertainty influences entrepreneurial decision making, impeding the pursuit of possible profit opportunities by causing firms to avoid uncertain decisions (McMullen and Shepherd 2006). Firms can avoid decision making under uncertainty by postponing such decisions and waiting until they have more clarity to prevent strategic errors due to inaccurate or incomplete information (Bourgeois and Eisenhardt 1988; Marcus 1981; Wernerfelt and Karnani 1987). Moreover, firms can obviate uncertainty arising from continuous changes or high volatility in regulatory conditions by stabilizing these conditions (Lev 1975). They can, for instance, negotiate standard procedures or long-term agreements (Cyert and March 1963) or surround their technological core with input and output buffers such as inventories (Thompson 1967). Another option for firms to avoid regulatory uncertainty is to withdraw completely from any activities associated with it (Jauch et al. 1980; Miller 1992).

Secondly, sense making theory suggests that firms seek to interpret an uncertain environment either by monitoring it to acquire additional information or by actively intruding into the environment to manipulate it (Daft and Weick 1984). Correspondingly, firms can reduce regulatory uncertainty through investigation by collecting information (Henisz and Delios 2004a; Miller and Friesen 1983) or by drawing on professional expertise (March and Simon 1958; Miller et al. 1982). Likewise, firms can reduce regulatory uncertainty by limiting the number of unpredictable factors and the interdependences to be considered in decision making. For example, firms can simplify uncertain regulatory environments by subdividing them into autonomous units (Levinthal and March 1993), thereby forcing unpredictable regulatory factors into fewer dimensions (Bourgeois and Eisenhardt 1988; Emery 1967). Firms are also able to reduce regulatory uncertainty by influencing the conditions or political actors that constitute it in order to achieve a specific state (Courtney et al. 1997; Henisz and Delios 2004b).

Thirdly, structural contingency theory posits that firms can adapt to regulatory uncertainty by adjusting their internal design toward modular structures with low formalization and decentralized decision making in autonomous units (Burns and Stalker 1961; Lawrence and Lorsch 1967). Organizing their subunits according to the degree of uncertainty they are exposed to limits the dynamism and complexity of the particular regulatory environment each unit has to individually respond to, thereby allowing the firms to better cope with the higher information processing requirements they face under uncertainty (Galbraith 1973). In addition, firms can reduce risks associated with uncertainty by 
Table 1 Strategic responses to regulatory uncertainty

\begin{tabular}{|c|c|c|c|}
\hline Strategy & Approach & Description & Authors \\
\hline \multirow[t]{3}{*}{ Avoid } & Postponement & $\begin{array}{l}\text { Defer decisions and wait for more } \\
\text { certainty }\end{array}$ & $\begin{array}{l}\text { Bourgeois and Eisenhardt (1988), } \\
\text { Marcus (1981), Wernerfelt and Karnani } \\
\text { (1987) }\end{array}$ \\
\hline & Stabilization & $\begin{array}{l}\text { Increase predictability through } \\
\text { implementation of standard } \\
\text { procedures or establishment of } \\
\text { long-term contracts }\end{array}$ & $\begin{array}{l}\text { Cyert and March (1963), Lev (1975), } \\
\text { Thompson (1967) }\end{array}$ \\
\hline & Withdrawal & $\begin{array}{l}\text { Exit business in uncertain markets } \\
\text { and focus on predictable } \\
\text { environments }\end{array}$ & Jauch et al. (1980), Miller (1992) \\
\hline \multirow[t]{3}{*}{ Reduce } & Investigation & $\begin{array}{l}\text { Collect additional information; draw } \\
\text { on professional expertise to be } \\
\text { applied in decision-making process }\end{array}$ & $\begin{array}{l}\text { Henisz and Delios (2004a), March and } \\
\text { Simon (1958), Miller and Friesen } \\
\text { (1983), Miller et al. (1982) }\end{array}$ \\
\hline & Simplification & $\begin{array}{l}\text { Reduce number of uncertain factors } \\
\text { considered in decision making } \\
\text { process }\end{array}$ & $\begin{array}{l}\text { Bourgeois and Eisenhardt (1988), Emery } \\
\text { (1967), Levinthal and March (1993) }\end{array}$ \\
\hline & Influencing & $\begin{array}{l}\text { Manipulate determining } \\
\text { circumstances or actors that } \\
\text { constitute uncertainty }\end{array}$ & $\begin{array}{l}\text { Courtney et al. (1997), Henisz and Delios } \\
\text { (2004b) }\end{array}$ \\
\hline \multirow[t]{5}{*}{ Adapt } & $\begin{array}{r}\text { Internal } \\
\text { design }\end{array}$ & $\begin{array}{l}\text { Change organizational design by } \\
\text { establishing modular structures, } \\
\text { low degree of formalization, or } \\
\text { decentralization }\end{array}$ & $\begin{array}{l}\text { Burns and Stalker (1961), Galbraith } \\
\text { (1973), Lawrence and Lorsch (1967) }\end{array}$ \\
\hline & Integration & $\begin{array}{l}\text { Restructure business portfolio } \\
\text { through mergers and acquisitions }\end{array}$ & $\begin{array}{l}\text { Bergh and Lawless (1998), Cyert and } \\
\text { March (1963), Thompson (1967) }\end{array}$ \\
\hline & Cooperation & $\begin{array}{l}\text { Collaborate with suppliers, } \\
\text { customers, or competitors in } \\
\text { research or production; engage in } \\
\text { trade associations }\end{array}$ & $\begin{array}{l}\text { Carter (1990), McNeeley (1995); } \\
\text { Thompson (1967) }\end{array}$ \\
\hline & Flexibility & $\begin{array}{l}\text { Enlarge range of strategic options, } \\
\text { e.g., through diversification }\end{array}$ & $\begin{array}{l}\text { Marcus (1987), Mascarenhas (1982), } \\
\text { Wernerfelt and Karnani (1987) }\end{array}$ \\
\hline & Imitation & $\begin{array}{l}\text { Examine and copy strategy of } \\
\text { successful competitors }\end{array}$ & $\begin{array}{l}\text { Anderson and Paine (1975), Bourgeois } \\
\text { and Eisenhardt (1987) }\end{array}$ \\
\hline \multirow[t]{3}{*}{ Disregard } & Substitution & $\begin{array}{l}\text { Replace uncertain decision criteria } \\
\text { with assumptions derived from } \\
\text { comprehensive consideration or } \\
\text { detailed analysis }\end{array}$ & $\begin{array}{l}\text { Collis (1992), Wernerfelt and Karnani } \\
\text { (1987) }\end{array}$ \\
\hline & $\begin{array}{l}\text { No-regret } \\
\text { moves }\end{array}$ & $\begin{array}{l}\text { Execute activities associated with } \\
\text { uncertainty that are advantageous } \\
\text { regardless of how uncertainty } \\
\text { resolves }\end{array}$ & Courtney et al. (1997) \\
\hline & $\begin{array}{l}\text { Business as } \\
\text { usual }^{\mathrm{a}}\end{array}$ & $\begin{array}{l}\text { Pretend that uncertainty does not } \\
\text { affect decisions }\end{array}$ & Emery (1967) \\
\hline
\end{tabular}

${ }^{a}$ Not included in empirical analysis

enlarging their range of potential options. For example, they can adapt their organization through integration by restructuring their business portfolio through mergers and acquisitions, thereby spreading the risk associated with the uncertainty across new divisions (Bergh and Lawless 1998; Cyert and March 1963; Thompson 1967). Likewise, to spread these risks, firms can cooperate with partners that are either similarly exposed to regulatory 
uncertainty (Carter 1990; Thompson 1967) or compensated otherwise, for example by being reimbursed financially or granted access to technology or special equipment (McNeeley 1995). Firms can also use flexibility to limit their exposure to the effects of regulatory uncertainty (Marcus 1987; Mascarenhas 1982), for example by pursuing a product diversification strategy to hedge their bets (Wernerfelt and Karnani 1987). Additionally, firms can minimize relative competitive disadvantages from inaccurate or unavailable information due to regulatory uncertainty by imitating the strategies of comparable peers (Anderson and Paine 1975; Bourgeois and Eisenhardt 1987).

Finally, firms can also pursue a strategy that enables them to disregard uncertainty despite their continuing exposure to it. The notion of firms as interpretation systems suggests that executives that perceive environmental uncertainty due to a lack of unambiguous data to substantiate an equivocal decision make sense of their environment by means of individual interpretation (Weick 1995). Hence, they can actively create ostensible clarity by explicitly substituting all unknown aspects with assumptions derived from comprehensive consideration or detailed analysis (Collis 1992), thereby being able to disregard the ambiguous circumstances of future regulation and pretending to act under complete certainty (Wernerfelt and Karnani 1987). Furthermore, firms can actively take no-regret moves which are advantageous regardless of how the regulatory uncertainty resolves, for instance by hedging decisions and reducing the overall risk through multiple investments that guarantee a return in all anticipated regulatory scenarios (Courtney et al. 1997). In addition to these approaches, firms can also passively pursue business as usual. Firms following this approach do not actively engage in specific activities to respond to regulatory uncertainty but rather continue with their regular activities, thereby pretending that the uncertainty does not affect their decision making (Emery 1967). Because doing business as usual implies that a firm does not pursue other response strategies to regulatory uncertainty, in the following we use the term disregard strategy only to refer to active approaches, which do allow for the simultaneous adoption of other approaches.

\section{Determinants of response strategies to regulatory uncertainty}

Regulatory uncertainty does not influence a firm's strategic decisions if it is not perceived by its executives (Anderson and Paine 1975). In particular, sense making theory suggests that executives need to analyze uncertain environments and interpret ambiguous events to take appropriate action (Daft and Weick 1984). Consequently, a firm's response strategy to regulatory uncertainty also depends on the executives' perceptions and interpretations of this uncertainty (Bourgeois 1980; Litschert and Bonham 1979). In this study, we focus on two particularly crucial aspects of executives' perceptions that influence such a response, the degree of regulatory uncertainty perceived (Bourgeois 1985; Ireland et al. 1987) and the interpretation of this uncertainty as a threat (Boynton et al. 1993; Jackson et al. 1987).

\section{Degree of regulatory uncertainty perceived}

Because the extent to which executives perceive regulatory uncertainty affects their decision patterns during strategy formulation, it also affects the firm's response strategies to regulatory uncertainty (Anderson and Paine 1975; Bourgeois 1980). Specifically, several studies indicate a relationship between the degree of perceived uncertainty associated with environmental regulation and a firm's strategic activities to overcome constraints associated with this uncertainty and to remain operational (Aragón-Correa and Sharma 2003; Marcus 1981; Marcus and Kaufman 1986). For example, Aragón-Correa and Sharma 
(2003) posit that perceiving high uncertainty increases the likelihood that firms develop a proactive environmental strategy in an attempt to anticipate unpredictable events such as the enactment of a new regulation. In contrast, Marcus and Kaufman's (1986) study of the U.S. government's synfuels program shows that the perception of high uncertainty about future environmental standards kept firms from investing into the development of synthetic fuels. More generally, Marcus (1981) analyzes how uncertainty affects firms' intention to innovate and finds anecdotal support for both a stimulating and a retarding effect, suggesting an influence not just of the perception of uncertainty but of the degree to which the uncertainty is perceived.

To begin with, avoiding decisions by deferring them is more likely to yield additional information and thus to increase certainty if the amount of missing information is large and the regulatory uncertainty is high (Yang et al. 2004). Similarly, high regulatory uncertainty is more difficult to cope with than low regulatory uncertainty, therefore forcing firms without sufficient coping capacity to avoid uncertain regulatory environments and to shift their business to more predictable ones (Anderson and Tushman 2001). In conclusion, firms exposed to high regulatory uncertainty will avoid this uncertainty to a greater extent than firms facing low regulatory uncertainty.

Secondly, high regulatory uncertainty denotes a lower availability of information on the respective regulation than is available under low regulatory uncertainty. Accordingly, the perception of high regulatory uncertainty emphasizes the need for collecting additional data to reduce this uncertainty (Blandin et al. 1977) and demonstrates an opportunity for contributing information to policymakers to affect the regulatory outcome (Ullmann 1985). However, regulatory uncertainty cannot be entirely eliminated beyond a residual uncertainty, i.e., "the uncertainty that remains after the best possible analysis" (Courtney et al. 1997, p. 69). Therefore, firms perceiving only a low level of regulatory uncertainty are likely to engage less in activities to reduce it even further. Consequently, firms exposed to high regulatory uncertainty are expected to attempt to reduce this uncertainty to a greater extent than firms with low regulatory uncertainty.

Thirdly, a firm's adaptation through changing its organizational design or restructuring its business portfolio is typically complex and costly (Bergh and Lawless 1998; YasaiArdekani 1986). Therefore, the efforts required to pursue this strategy seem to be justifiable only in cases of high regulatory uncertainty. Likewise, the number of possible regulatory outcomes usually increases with a higher degree of regulatory uncertainty, making it more appropriate for firms to adapt by enlarging their strategic options than in the case of low regulatory uncertainty (Courtney et al. 1997). Thus, firms with high regulatory uncertainty are likely to try adapting to this uncertainty to a greater extent than firms perceiving low regulatory uncertainty.

Lastly, high uncertainty over the parameter underlying a strategic decision makes it difficult for firms to actually make this decision and increases the need to instead derive solid assumptions to base the decision on (Faucheux and Froger 1995). To this end, firms can disregard uncertain decision parameters by substituting them with the results obtained from applying analytical tools and methods, such as real options or scenario planning (Amram and Kulatilaka 1999). Also, high regulatory uncertainty resulting in a lack of information over the appropriate steps for a firm to take next increases the risk of making wrong strategic decisions. This potentially leads firms to focus on no-regret moves that do not require the explicit consideration of regulatory uncertainty. Therefore, firms with high regulatory uncertainty are more likely to actively respond in ways that allow them to disregard the uncertainty in their decision making than firms that only face low regulatory uncertainty. This leads to our first set of hypotheses: 
Hypotheses 1a-d The greater the extent to which firms perceive regulatory uncertainty, the greater the extent to which they pursue strategies a) to avoid this uncertainty, b) to reduce this uncertainty, c) to adapt to this uncertainty and d) that enable them to disregard this uncertainty.

\section{Perception of regulatory uncertainty as a threat}

Executives' interpretation of strategic issues in their firm's business environment as threatening significantly influences the firm's strategic response to these issues (Dutton et al. 1990; Thomas and McDaniel 1990; Thomas et al. 1993). Strategic issues that executives perceive as threats are predominantly characterized by low controllability (Jackson and Dutton 1988). Uncertainty in a firm's regulatory environment is therefore especially likely to be perceived as a threat because this environment is complex and particularly difficult to control (Birnbaum 1984; Miller 1992). Lacking information about future regulatory conditions can impede a firm's strategic planning, thus thwarting the effective allocation of its resources and endangering its competitiveness (Bourgeois 1985). For example, uncertainty associated with the allocation of free allowances to coal or gas power plants poses a considerable threat to utilities that have to decide on large investments to replace existing plants, as this decision locks in a strategic value of the firms' assets that a disadvantageous allocation mechanism would dramatically reduce (Hoffmann et al. 2009). However, the extent to which individual executives perceive the uncertainty associated with a particular regulation as threatening can vary considerably (Barr and Glynn 2004; Sharma 2000), depending, for example, on specific strategic requirements imposed by their firm-specific organizational context (Dutton and Jackson 1987; Hambrick 1981). Moreover, research on the relationship between national and organizational cultures indicates cultural differences in experience with exposure to uncertainty (Hofstede 1980), potentially resulting in variations regarding firms' entrepreneurial attitude and their willingness to bear such uncertainty (McMullen and Shepherd 2006). On a similar note, empirical research on issue categorization found differences in the association of controllability with threat based on cultural patterns and values (Sallivan and Nonaka 1988; Schneider and De Meyer 1991), likely leading to varying threat perceptions of the same regulatory uncertainty across national cultures. Accordingly, the different degrees of threat perceived from exposure to uncertainty associated with a regulation are likely to affect the extent of firms' pursuit of strategic responses to this uncertainty (Chattopadhyay et al. 2001; Dutton and Duncan 1987).

The higher the threat a firm perceives from being exposed to regulatory uncertainty, the more the firm tends to pursue an active response that enables it to avoid, reduce, or adapt to this uncertainty (Jackson and Dutton 1988; Jackson et al. 1987). First, avoiding regulatory uncertainty resolves it for the individual firm and thereby eliminates the perceived threat associated with it (Barr and Glynn 2004). Firms that cannot constrain the threat perceived from being exposed to regulatory uncertainty can avert it by temporarily suspending individual decisions or withdrawing completely from uncertain regulatory environments. The latter behavior is particularly likely if a firm perceives a threat to be high and to entail negative effects too critical for the firm to tolerate. Hence, firms perceiving the exposure to regulatory uncertainty as a threat are likely to try to avoid this uncertainty to a greater extent than firms not perceiving regulatory uncertainty as a threat.

Secondly, a reduction strategy decreases the regulatory uncertainty and thus extenuates the conditions that constitute the threat. The perception of regulatory uncertainty as a threat leads firms to seek increased control over the factors determining the uncertainty, for example by strengthening their ties with policymakers (Staw et al. 1981). Similarly, firms perceiving the inadequacy of information available about future environmental regulation 
as threatening are likely to intensify their information gathering behavior (Smart and Vertinsky 1977). In turn, research indicates that a firm's search activities decrease over time as the firm perceives its environment as less threatening (Daft and Weick 1984). Consequently, we assume that firms perceiving a threat from being exposed to regulatory uncertainty attempt to reduce this uncertainty to a greater extent than firms not perceiving regulatory uncertainty as threatening.

Thirdly, adapting to regulatory uncertainty limits the potentially negative effects of being exposed to it and alleviates threats resulting from this uncertainty. Firms that change their organizational design and increase their flexibility can build up responsiveness to unpredictable regulatory events that otherwise might affect them negatively (Argote et al. 1989; Khandwalla 1978). Also, diversifying a firm's business portfolio or joining forces with others lowers the firm's individual risks of being exposed to regulatory uncertainty and thus diminishes the related threat (Birnbaum 1984; Wernerfelt and Karnani 1987). Therefore, we propose that firms perceiving regulatory uncertainty as a threat adapt to this uncertainty to a greater extent than firms that do not perceive this uncertainty as a threat.

Our second set of hypotheses follows on from this argumentation:

Hypotheses 2a-c Firms that perceive regulatory uncertainty as a threat pursue strategies a) to avoid, b) to reduce, and c) to adapt to this uncertainty to a greater extent than firms that do not perceive this uncertainty as a threat.

Finally, if firms anticipate that regulatory uncertainty might affect them negatively and thus perceive this uncertainty as a threat, disregarding it does not counteract the source of this threat but rather exacerbates the negative effects of being fully exposed to the uncertainty (D'Aveni and MacMillan 1990). In consequence, firms that perceive regulatory uncertainty as a threat are most likely respond actively to this uncertainty in order to initiate appropriate countermeasures and to alleviate the expected negative effects. Conversely, firms may potentially decide to not consider regulatory uncertainty in their decision making if direct counteraction seems unnecessary, indicating that the uncertainty is not perceived as a threat (Jackson et al. 1987). Accordingly, we expect firms that perceive a threat from regulatory uncertainty to be less likely to behave in ways that allow them to disregard this uncertainty in their decision making than firms that do not perceive regulatory uncertainty as a threat. We thus conclude:

Hypothesis 2d Firms that perceive regulatory uncertainty as a threat pursue strategies that enable them to disregard this uncertainty to a lesser extent than firms that do not perceive this uncertainty as a threat.

\section{Post-Kyoto regulatory uncertainty}

Because many of today's most pressing environmental challenges such as climate change or ozone depletion take effect across national borders, the natural environment is arguably the area with the greatest need for global regulation (Lave 1988; Rugman and Verbeke 1998). Adverse effects of regulatory uncertainty on efficient policymaking are especially critical in this case, as ineffective regulation could have severe and possibly irreversible consequences (Faucheux and Froger 1995). Nevertheless, environmental regulation is a particular source of such uncertainty (Tarui and Polasky 2005), mainly because it is typically based on very longterm considerations, with science playing an important role in agenda setting, policymaking, and evaluation (Arentsen et al. 2000; Van den Hove 2000). The initiation, implementation, 
and enforcement of environmental regulations are difficult to predict and constitute considerable regulatory uncertainty (Birnbaum 1984). This especially applies to multilateral environmental regulations addressing climate change, which mostly only specify environmental goals and require the individual governments of the concerned countries to pass national regulations to achieve these goals (Levy 1997). In consequence, we investigated our hypotheses by studying corporate strategies to respond to regulatory uncertainty associated with a global environmental regulation succeeding the Kyoto Protocol.

The Kyoto Protocol particularly exemplifies the considerable uncertainties typically inherent to international schemes on climate policy (Grubb et al. 1999; Yamin 1998). The Kyoto Protocol is an international treaty created under the United Nations Framework Convention on Climate Change, imposing national caps on the greenhouse gas (GHG) emissions of industrialized countries to counteract climate change. While the Kyoto Protocol itself will expire in 2012, international talks on a succeeding scheme have been under way since 2005, provisionally culminating in the adoption of a roadmap for establishing a global $\mathrm{CO}_{2}$ emission regulation beyond 2012 (UNFCCC 2007). However, there are still many uncertainties associated with a post-Kyoto regulation (Hoffmann et al. 2008). First, it is doubtful whether a global agreement can be reached at all, since three of the world's top five GHG emitters, the U.S., China, and India, are reluctant to join it (Harrison 2007). Second, it remains unclear what a postKyoto scheme would look like and how individual countries would design and enforce their national regulations. Numerous policy options exist, both at national and at regional levels (Keeler 2007), which differ considerably in terms of requirements and implementation complexity (Kolk and Hoffmann 2007). Finally, the impact of a global post-Kyoto scheme on regulated industries and companies remains largely unknown (Anger 2008).

\section{Methods and data}

We tested our hypotheses via multiple linear regression analysis of data collected through a survey of publicly listed corporations. To study determinants for firms' pursuit of a specific strategy to respond to regulatory uncertainty and to facilitate a comparative analysis, we used four regression models each representing one strategic response.

Data collection and sample

A post-Kyoto regulation aiming at the reduction in $\mathrm{CO}_{2}$ emissions primarily targets carbonintense industries, which were thus particularly exposed to uncertainty regarding this regulation at the time of our survey. Hence, we collected our data from firms characterized either by high $\mathrm{CO}_{2}$ emissions during their respective production processes, for example power plant operators, cement producers, or airlines, or by high $\mathrm{CO}_{2}$ emissions during the use of their products, as in the case of car manufacturers. Furthermore, our sample included firms from all the world's main economic regions to correspond to the likely global scope of a post-Kyoto regulation. Due to better availability of financial and environmental data from archival sources, we focused on publicly listed firms. Our final sample comprised the 821 firms from the electric utilities, industrial goods, basic materials, chemicals, transportation, and oil industries listed in the Dow Jones Global Indexes at the end of March 2007.

From these firms, we collected data for our analysis by means of questions addressing regulatory uncertainty and according strategies to respond to this uncertainty. The questions were incorporated within a more comprehensive questionnaire on climate change and sustainability issues, which was made available online between April and June 2007. We 
administered the questionnaire at the corporate level for firms operating only in carbonintense industries and at the business unit level for multidivisional firms also operating in other industries. As our survey addressed issues related to a firm's corporate strategy, our target respondents were the firms' CEOs or, in the case of multidivisional firms, the heads of the businesses operating in carbon-intense industries. Firm executives were addressed directly via email, and subsequent follow-ups were conducted via email and phone to increase the response rate. Of the 821 firms in our sample, 133 completed the relevant questions and returned the survey, representing a response rate of 16.2 percent. Because of incomplete information, we excluded 21 out of the 133 responses from our study, leaving a total of 112 responses for our analyses. Following the administration of the survey, we also conducted several in-depth interviews with executives in main industries and regions in order to triangulate our quantitative results and to substantiate our conclusions.

\section{Representativeness of sample}

Instead of solely relying on objective measures of a firm's environment, measuring executives' subjective perceptions has long been established as more adequate for research on determinants of firms' strategic behavior (Anderson and Paine 1975; Downey et al. 1977; Weick 1969). However, collecting self-reported data entails the potential presence of response bias regarding self-selection and common method which, if existent, obviate generalizability of the findings.

T-tests analyzing respondents' industry affiliation, experience with regulatory uncertainty, 2006 sales, market capitalization, and profitability, measured as return on assets, did not reveal significant differences to the sample. To control for the significantly lower share of Asian and higher share of European firms compared to the sample, we included a variable about respondents' regional provenance in our statistical analyses. As late respondents to surveys tend to be more similar to non-respondents than early respondents (Fowler 1993), we compared the answers from firms in the first quartile that replied during the early stages of our research to those from firms in the last quartile, typically returning the survey at the end after at least one follow-up. T-tests comparing degree of regulatory uncertainty, interpretation of this uncertainty as a threat, strategic response, and $\mathrm{CO}_{2}$ emissions did not show significant differences between the two groups. Although some self-selection bias might be expected, these data suggest sample representativeness.

Secondly, we minimized the influence of common method bias by separating items for the independent and dependent variables into different sections of the questionnaire. In addition, control variables such as experience in responding to regulatory uncertainty, firm size, industry, and location were taken from archival sources, thereby further diminishing the potential for such bias. To determine the extent to which common method bias was still present in our data, we conducted Harman's one-factor test (Appendix, Table 5). A factor analysis of all perceptual variables resulted in six separate factors with eigenvalues greater than 1 accounting for 59.6 percent of the variance, with the first factor explaining 20.7 percent (Appendix, Table 6). The emergence of more than one factor with the first factor accounting for less than half of the explained variance suggested that common method bias was unlikely in our study (Podsakoff et al. 2003).

\section{Measures}

To provide for content validity, industry experts and strategic management scholars focusing on climate change reviewed our questionnaire items, which were then pretested 
with executives from selected companies for clear understanding and relevance to carbonintense industries (Hambrick 1981). Unless otherwise noted, all measures used were rated on a five-point Likert scale. An open text field succeeded each measure to provide respondents with the option to enter additional remarks.

\section{Corporate strategies to respond to regulatory uncertainty}

We used multiple-item measures to assess firms' strategies (Venkatraman and Grant 1986). To this end, the questionnaire included questions on activities representing one of the four strategies to respond to regulatory uncertainty. An item asking whether a firm was pursuing a respective activity at all preceded each question. Only firms indicating that they were actually pursuing the activity were asked to score it, whereas the value 0 was used for the other respondents. For each strategy type, we computed average ratings for each firm based on its individual scores of the underlying activities. We excluded respondents indicating their inability to score a question due to lack of knowledge from further analysis.

We measured each strategy with items corresponding to the underlying approaches shown in Table 1. In particular, we measured respondents' pursuit of a reduction strategy with three items, asking to what extent they systematically searched for additional information, engaged in the current policy making process to contribute to the decision making, and focused on specific issues in their business environment to simplify the decision making (Cronbach's $\alpha=.66$ ). We used five items to measure the pursuit of an adaptation strategy, asking respondents to what extent they changed their organizational structure, rearranged their business portfolio, prepared for multiple regulatory outcomes, joined forces with other firms, and followed the activities of peers $(\alpha=.76)$. The avoidance measure consisted of three items, asking executives to indicate the extent to which they postponed decisions, created predictability by negotiating long-term agreements, and shifted business to less uncertain markets $(\alpha=.63)$. Finally, we measured the pursuit of a disregard strategy with two items, asking to what extent respondents focused on one likely regulatory scenario and made investments profitable regardless of future regulation $(\alpha=.71)$. We excluded the business as usual approach from the disregard measure as it implied that none of the other response strategies was pursued. All scales showed acceptable internal consistency (Nunnally 1978).

\section{Degree of regulatory uncertainty perceived}

We drew on Milliken's definition of perceived uncertainty as "an individual's perceived inability to predict something accurately" (Milliken 1987, p. 136) to measure respondents' individual degree of perceived regulatory uncertainty. The measure comprised three items, asking respondents to what extent they perceived themselves able to predict the future existence of a possible $\mathrm{CO}_{2}$ emission regulation succeeding the Kyoto Protocol, its design, and the impact of such a regulation on their firm (Cronbach's $\alpha=.80$ ).

\section{Perception of regulatory uncertainty as a threat}

Bergkvist and Rossiter (2007) compare the predictive validities of single-item and multiitem measures and find that they do not differ for constructs such as the overall perception of a brand as pleasant or unpleasant or the attitude toward a product category as good or bad. In consequence, they suggest using single-item measures for constructs that consist of 
concrete singular objects (e.g., brand perception) and concrete attributes (e.g., good/bad), i.e., objects and attributes that are "easily and uniformly imagined" (Bergkvist and Rossiter 2007: 176). Building on this suggestion and following Staw and colleagues' conceptualization of threat as an environmental event with imminent negative effect on a firm (Staw et al. 1981), we asked executives to rate whether they perceived the regulatory uncertainty as a threat for their firm. Four answer options were given, ranging from 'does not pose a threat to our firm's operations' to 'poses a threat to our firm's entire operations'. We chose this structure to provide respondents with a tangible scale of assessment for calibration purposes that facilitated the depiction of an overall company perspective. Corresponding to the formulation applied in our hypotheses, which reflects the dichotomous perception or regulatory uncertainty as either a threat or not, the rating was transformed into a dummy variable. This variable took the value 1 for respondents indicating a threat for major parts of their firm's operations or their entire firm and the value 0 for those indicating no threat or only a threat for small parts of their firm's operations.

Ex post analysis substantiated divergent validity of uncertainty and threat perception measures. In addition to the results shown in Table 3, calculating the correlation coefficient between the uncertainty measure and the original measure on threat perception, i.e., prior to its transformation into a dummy variable, confirmed their divergent validity, shown by a lack of correlation between them $\left(\mathrm{r}_{\mathrm{s}}=.057, p=.525\right)$. Similarly, the results of a factor analysis demonstrated that the uncertainty measures and the measure on threat perception load on different factors, corroborating their logical independence (Appendix, Table 5).

While it is conceivable that respondents' strategic response to uncertainty affects their perception of this uncertainty in the long term, this effect is unlikely to be immediate. To further corroborate direction of causality in our hypotheses, we initially asked respondents to rate the current level of uncertainty perceived and then asked to what extent they were pursuing the various approaches in response to this uncertainty.

\section{Control variables}

Respondents that had previously faced uncertainty regarding a regulation dealing with their $\mathrm{CO}_{2}$ emissions might perceive the current regulatory uncertainty differently and therefore choose a different response. We used a dummy variable to control for respondents' experience in responding to regulatory uncertainty. This variable took the value 1 for respondents who previously had been exposed to such uncertainty due to inclusion in the European Union Emission Trading Scheme (EU ETS). Conversely, it took the value 0 for European firms not included in the EU ETS and for firms from other regions.

The strategic importance executives assign to issues such as uncertainty in their firm's environment depends on the firm's strategy (Hambrick 1981). In particular, firms with a strategy entailing only low $\mathrm{CO}_{2}$ emissions might consider uncertainty regarding a postKyoto regulation targeting a substantial $\mathrm{CO}_{2}$ emission reduction as less important than those pursuing a carbon-intense strategy. In turn, this could have an effect on their respective responses to this regulatory uncertainty. To control for this effect, we used the logarithm of respondents' total amount of $\mathrm{CO}_{2}$ emissions in 2006. Although these data were publicly available for most respondents, some firms did not publish data on their $\mathrm{CO}_{2}$ emissions. To obtain comparable information for all respondents, we included a survey item on respondents' $\mathrm{CO}_{2}$ emissions. Random verification of the self-reported data with public data yielded no notable discrepancies.

The broader resource pool available to a larger firm is likely to affect the number and the extent of the response strategies the firm pursues (Wernerfelt and Karnani 1987). To 
control for firm size, we used the logarithm of 2006 annual sales, obtaining the latter from the financial database Compustat.

To control for industry dependent variations of corporate behavior under uncertainty (Hoffmann and Trautmann 2006; Hrebiniak and Snow 1980), we included an industry variable based on the sector allocation applied by the Dow Jones Global Indexes.

Finally, because respondents' regional composition deviated from that of the sample, we controlled for the location of the respondents' registered office. The distribution of respondents across locations and industries is shown in Table 2.

\section{Results}

Table 3 shows the descriptive statistics and the linear correlations between the measures used in this study. Overall, respondents tended to rate themselves as perceiving the uncertainty regarding a post-Kyoto scheme to a medium extent (average score of 3.00 on a five-point scale). However, they deviated considerably in this perception, with respondents from North America perceiving the uncertainty as being at a lower level than their Asian counterparts. Furthermore, about one-third of the 112 respondents (35) described themselves as perceiving this uncertainty as a threat. This perception was particularly widespread among Asian firms and less common in Europe. However, it was not related to the degree of regulatory uncertainty perceived. Comments in the open text fields indicated a broad range of factors influencing respondents' perception of this uncertainty. For example, a European cement producer pointed to the financial risks from having to make irrevocable investment decisions regarding its production network in absence of regulatory stability, leading the company to perceive the post-Kyoto uncertainty as a major threat. In contrast, a utility from North America stated that it considered this uncertainty as beneficial rather than threatening because it kept competitors from initiating activities to reduce $\mathrm{CO}_{2}$ emissions. Such activities would have offset the own company's head start, resulting from its progress toward a self-set $\mathrm{CO}_{2}$ emission reduction target in preparation for a post-Kyoto regulation.

Firms exhibited a common propensity to react when exposed to regulatory uncertainty. In general, they pursued each of the four strategies to respond to this uncertainty, though to a different extent. Interestingly, it seems that each strategy was especially pursued by firms

Table 2 Composition of sample

\begin{tabular}{lllllr}
\hline Industry & \multicolumn{2}{l}{ Location } & & & \\
\cline { 2 - 5 } & Europe & North America & Asia & Others $^{\text {a }}$ & Total \\
\hline Industrial goods & 10 & 6 & 9 & 1 & 26 \\
Utilities & 11 & 8 & 3 & 1 & 23 \\
Basic materials & 11 & 4 & 2 & 1 & 18 \\
Chemicals & 9 & 4 & 2 & 1 & 16 \\
Transportation & 10 & 1 & 3 & 1 & 15 \\
Oil & 6 & 4 & 1 & 3 & 14 \\
Total & 57 & 27 & 20 & 8 & 112 \\
\hline
\end{tabular}

a Australia and South America 


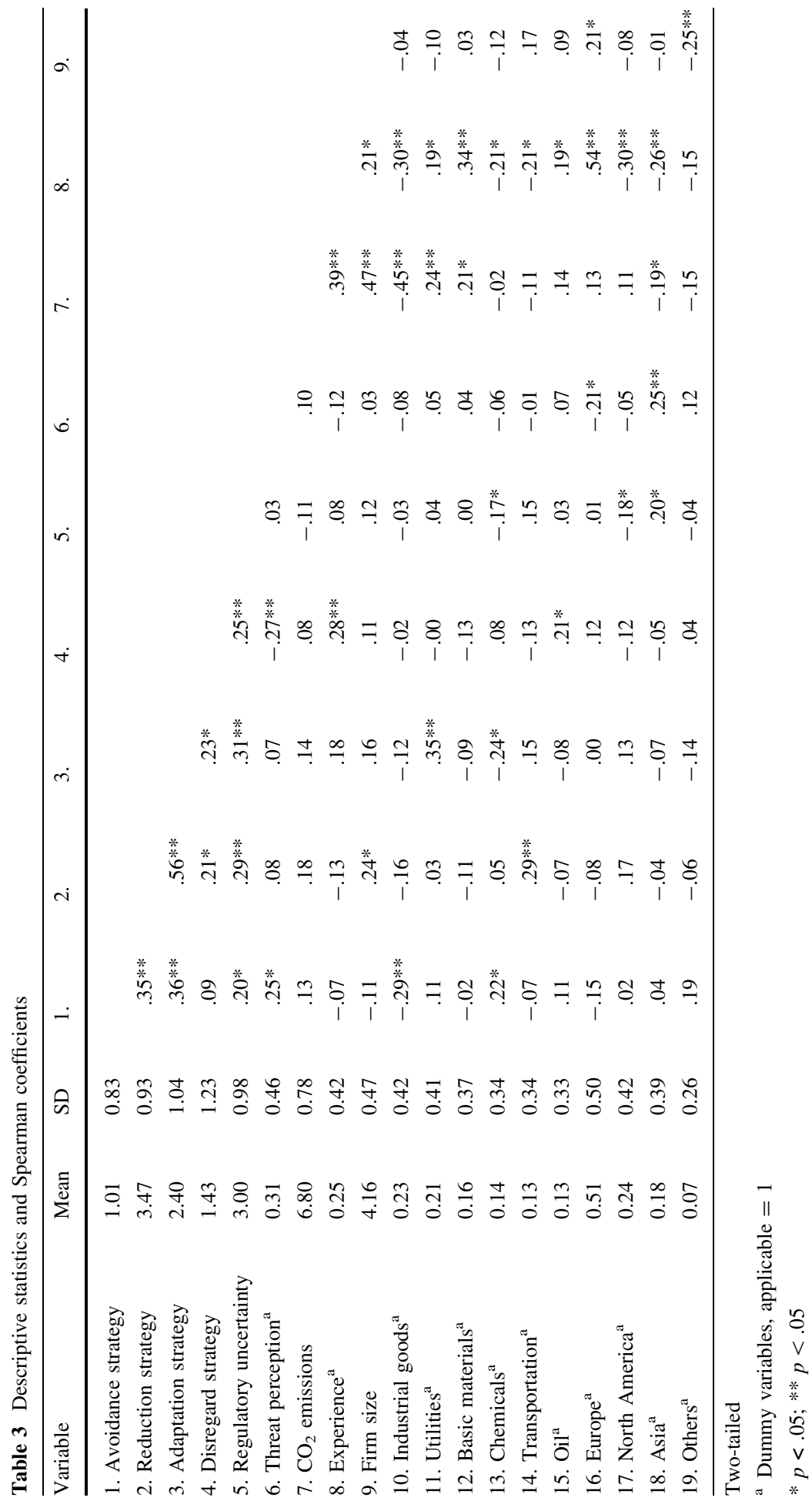


in one particular industry. Overall, reduction was applied to the highest extent (average score of 3.47 on a scale from 0 to 5), with about three-quarters of the 112 respondents (85) pursuing this strategic response more intensely than any of the other strategies. Firms in the transportation industry, which also perceived the highest uncertainty among respondents (average score of 3.39), particularly engaged in reduction, with an average score of 4.16. The response strategy pursued to the second greatest extent was adaptation with an average score of 2.40. This strategy was predominantly pursued by utility firms (average score of 3.11 ), in contrast to firms in the chemical industry who pursued adaptation to the lowest level of all respondents (average score of 1.79). Instead, with an average score of 1.49, these firms followed an avoidance strategy to a greater extent than firms in other industries. Among all respondents, however, avoidance was generally applied to the lowest degree (average score of 1.01), with nearly one quarter of the 112 respondents (27) not avoiding regulatory uncertainty at all. Finally, firms generally pursued a disregard strategy with an average score of 1.43, with about one-third of the 112 respondents (34) not applying this response at all. However, with an average score of 2.07, oil firms applied a response that allowed them to disregard the regulatory uncertainty to a greater extent than firms in other industries. Interestingly, firms experienced in coping with regulatory uncertainty also pursued this response and to a significantly higher degree than inexperienced firms (average score of 2.06 compared to 1.25).

In order to analyze the relationships between perceived regulatory uncertainty, its perception as a threat, and the four strategies to respond to it while controlling for the effects of other potentially influencing factors, we carried out four ordinary least squares regression analyses. Table 4 shows the results of these analyses.

Hypotheses 1a and 2a were supported by the data. Model 1 shows that perceived regulatory uncertainty positively contributed to the pursuit of an avoidance strategy $(p<.01)$. Likewise, its interpretation as a threat had a positive effect on avoidance $(p<.05)$. Out of the control variables, affiliation with the chemicals industry and the amount of $\mathrm{CO}_{2}$ emissions each had a positive effect $(p<.05)$, while firm size had a negative effect $(p<.01)$.

The data also supported Hypotheses $1 \mathrm{~b}$ and $2 \mathrm{~b}$. As predicted, model 2 shows significant and positive effects of both regulatory uncertainty and perception as a threat on firms' pursuit of a reduction strategy $(p<.01$ and $p<.05$, respectively). Likewise, firms' affiliation with the industrial goods, chemicals, and transportation industries contributed positively to reduction $(p<.01)$, as did their amount of $\mathrm{CO}_{2}$ emissions $(p<.05)$. On the contrary, location in Asia contributed negatively $(p<.05)$.

Hypotheses $1 \mathrm{c}$ and $2 \mathrm{c}$ also received support. The results depict a statistically significant positive effect of the degree of regulatory uncertainty perceived and the interpretation of this uncertainty as a threat on adaptation (model $3, p<.01$ ). Similarly, affiliation with the industrial goods, utilities, and transportation industries, experience in responding to regulatory uncertainty, and location in North America all contributed positively $(p<.01$, except for industrial goods with $p<.05$ ).

The data also supported Hypothesis 1d, according to which a firm's perceived regulatory uncertainty is positively related to the pursuit of a response enabling the firm to disregard this uncertainty (model $4, p<.01$ ). Furthermore, Hypothesis $2 \mathrm{~d}$, suggesting a negative relationship between the interpretation of regulatory uncertainty as a threat and the pursuit of a disregard strategy, also received support (model $4, p<.05$ ). Affiliation with the basic materials industry contributed negatively, while experience in responding to regulatory uncertainty contributed positively $(p<.05)$. 
Table 4 Results of regression analyses (Values are unstandardized regression coefficients, with standard errors in parentheses)

\begin{tabular}{|c|c|c|c|c|}
\hline \multirow{2}{*}{$\begin{array}{l}\text { Independent } \\
\text { variables }\end{array}$} & \multicolumn{4}{|c|}{ Dependent variables } \\
\hline & $\begin{array}{l}\text { Model 1: Avoid } \\
\text { decision making } \\
\text { under regulatory } \\
\text { uncertainty }\end{array}$ & $\begin{array}{l}\text { Model 2: Directly } \\
\text { target regulatory } \\
\text { uncertainty to } \\
\text { reduce it }\end{array}$ & $\begin{array}{l}\text { Model 3: Adapt internal } \\
\text { capacity to better cope } \\
\text { with regulatory } \\
\text { uncertainty }\end{array}$ & $\begin{array}{l}\text { Model 4: Disregard } \\
\text { regulatory } \\
\text { uncertainty for } \\
\text { decision making }\end{array}$ \\
\hline Constant & $0.56(0.86)$ & $-1.35(0.89)$ & $0.45(0.95)$ & $-0.02(1.23)$ \\
\hline $\begin{array}{l}\text { Regulatory } \\
\text { uncertainty }\end{array}$ & $0.34 * *(0.08)$ & $0.54 * *(0.09)$ & $0.49 * *(0.10)$ & $0.41 * *(0.12)$ \\
\hline $\begin{array}{l}\text { Threat } \\
\text { perception }^{\mathrm{a}}\end{array}$ & $0.36 *(0.16)$ & $0.37 *(0.17)$ & $0.61 * *(0.23)$ & $-0.60 *(0.25)$ \\
\hline $\mathrm{CO}_{2}$ emissions & $0.33 *(0.13)$ & $0.32 *(0.14)$ & $-0.18(0.15)$ & $0.03(0.19)$ \\
\hline Experience $^{\mathrm{a}}$ & $-0.26(0.27)$ & $0.20(0.27)$ & $1.06 * *(0.32)$ & $0.87 *(0.42)$ \\
\hline Firm size & $-0.55 * *(0.20)$ & $0.12(0.19)$ & $0.05(0.22)$ & $0.22(0.30)$ \\
\hline \multicolumn{5}{|l|}{ Industry $^{\mathrm{a}}$} \\
\hline $\begin{array}{l}\text { Industrial } \\
\text { goods }\end{array}$ & $-0.40(0.30)$ & $0.92 * *(0.32)$ & $0.73 *(0.35)$ & $-0.15(0.45)$ \\
\hline Utilities & $-0.15(0.26)$ & $0.25(0.26)$ & $1.00 * *(0.30)$ & $-0.38(0.38)$ \\
\hline $\begin{array}{l}\text { Basic } \\
\text { materials }\end{array}$ & $-0.26(0.26)$ & $0.30(0.27)$ & $0.19(0.32)$ & $-0.84 *(0.41)$ \\
\hline Chemicals & $0.67 *(0.32)$ & $1.05 * *(0.34)$ & $0.62(0.38)$ & $0.19(0.47)$ \\
\hline Transportation & $-0.31(0.31)$ & $1.47 * *(0.33)$ & $1.22 * *(0.37)$ & $-0.75(0.49)$ \\
\hline \multicolumn{5}{|l|}{ Location $^{\mathrm{a}}$} \\
\hline Europe & $-0.41(0.33)$ & $-0.51(0.33)$ & $0.21(0.43)$ & $-0.70(0.50)$ \\
\hline $\begin{array}{l}\text { North } \\
\text { America }\end{array}$ & $-0.40(0.32)$ & $0.41(0.32)$ & $1.12 * *(0.42)$ & $-0.74(0.48)$ \\
\hline Asia & $-0.33(0.33)$ & $-0.83 *(0.34)$ & $-0.07(0.43)$ & $-0.71(0.49)$ \\
\hline$R^{2}$ & 0.39 & 0.49 & 0.46 & 0.34 \\
\hline Adjusted $R^{2}$ & 0.30 & 0.41 & 0.37 & 0.24 \\
\hline$F$ & $4.28^{* *}$ & $6.33 * *$ & $5.59 * *$ & $3.48 * *$ \\
\hline
\end{tabular}

${ }^{a}$ Dummy variables, applicable $=1$

$* p<.05 ; * * p<.01$

\section{Discussion and conclusion}

In the following, we first elaborate on firms' pursuit of the four strategies and especially on the surprisingly low application of avoidance. Following this, we turn to specific factors found to influence firms' pursuit of the response strategies, particularly focusing on industry and regional differences, firms' experience in responding to regulatory uncertainty, and their $\mathrm{CO}_{2}$ emissions. We conclude by providing implications for policymakers and by suggesting directions for future research.

Pursuit of response strategies to regulatory uncertainty

As hypothesized, higher perceived regulatory uncertainty causes firms to engage in all response strategies to a greater extent. In addition, firms perceiving post-Kyoto regulatory 
uncertainty as a threat pursue reduction, adaptation, and avoidance strategies to a greater, and a disregard strategy to a lesser, extent than those not perceiving this uncertainty as a threat. In particular, our findings show that firms generally pursue all four strategies derived from the literature in response to uncertainty associated with post-Kyoto regulation, though to a considerably different extent. On average, firms predominantly counter this uncertainty through a reduction strategy, while they pursue adaptation, disregard, and most particularly avoidance strategies to a much lower degree.

The surprisingly low application of avoidance rebuts assertions firms often make in the context of the Kyoto Protocol and its potential successor scheme claiming that the unpredictable and lengthy policymaking process would drive them to avoid the resulting regulatory uncertainty. In particular, it puts into perspective firms' common threats toward policymakers to postpone investments or even to withdraw from uncertain regions by relocating production facilities to third countries that are expected to enact a future regulation less strictly (e.g., Sullivan and Blyth 2006). Additional insights into the interviews conducted after the survey phase revealed that the low extent to which firms actually pursue an avoidance strategy is in part the result of their focus on uncertainty reduction, particularly through an influencing approach. Many firms noted that the interaction with local governments and international regulatory agencies is their predominant activity undertaken to cope with the perceived regulatory uncertainty. In this context, firms fear that their hesitation or opposition to activities related to a future regulation, such as the postponement of investments, even if caused by uncertainty, could be interpreted as a rejection of the regulation and its objectives. In turn, this could endanger their attempts to build up the credibility needed for the formation of informative relationships with government officials. This dichotomy between firms' publicly announced intention to avoid regulatory uncertainty and their actual pursuit of a more subtle influencing approach suggests extending the existing concepts on political influencing (e.g., Hillman and Hitt 1999) by adding an uncertainty dimension. Such an extension might enhance the understanding of firms' choice of different influencing strategies, for example with respect to a potential subsequent or even simultaneous pursuit. In addition, it could facilitate policymakers' management of firms' influencing strategies, thereby potentially increasing the efficiency and effectiveness of their policymaking.

Factors influencing response strategy pursuit

In order to efficiently formulate effective regulations that cover several industries, policymakers should realize potential industry-specific differences. In this regard, our results indicate that firms' pursuit of the different strategic responses to post-Kyoto regulatory uncertainty deviates considerably across industries. To explore this finding in more detail, we conducted a non-parametric analysis with Kruskal-Wallis and Mann-Whitney tests, thereby considering the small number of observations per industry (Hair et al. 1998). Kruskal-Wallis tests comparing the average pursuit of the response strategies across all industries mostly confirmed the deviations, showing significant differences between the average pursuit of reduction $(p<.05)$, adaptation $(p<.01)$, and avoidance strategies $(p<.05)$. Mann-Whitney tests comparing the average pursuit of these response strategies in different industries showed that firms in the transportation industry focus on uncertainty reduction $(p<.01)$, utilities pursue adaptation $(p<.01)$, and firms in the chemical industry follow an avoidance strategy $(p<.05)$ to a greater extent than firms in other industries. 
Respondents' remarks in open text fields and our follow-up interviews suggest that these differences can potentially be ascribed to specific industry characteristics, such as the time period for which an industry has attracted attention from policymakers or the industry's degree of globalization. For example, the political negotiation on the regulation of $\mathrm{CO}_{2}$ emissions from aviation and road transport was still in an early stage at the time of our survey, possibly making policymakers particularly susceptible to external influence and thus encouraging firms in the transportation industry to exceedingly engage in lobbying activities. Furthermore, follow-up interviews revealed that the resulting high uncertainty typically led these firms to extensively apply investigation and simplification approaches, as reflected in this comment of an airline executive: "We cannot afford to comprehend all uncertain details. We focus on some critical aspects and examine them in more detail." On the contrary, policymakers had already focused on $\mathrm{CO}_{2}$ emissions from the utility industry for a much longer time, potentially leading utilities to pursue adaptation strategies. For instance, a manager of a firm that had recently merged with another utility explained that "the combined companies possess a more diversified energy mix and service territories, which allows us to better adapt to changes in the regulatory landscape." Because organizational adaptation processes are usually complex and lengthy (Bergh and Lawless 1998), such a strategy appears particularly adequate as response to an extended exposure to regulatory uncertainty. On a different note, it is conceivable that expected regional differences in future regulation, for instance likely stricter rules in Europe than in Asia, encouraged firms in industries with an only limited need for customer proximity to relocate to areas with regulation of lower stringency (Christmann and Taylor 2001). For example, the great extent to which the chemical industry pursued avoidance strategies was potentially facilitated by chemicals' high margins per unit of weight and volume and the low costs for shipping them, which allowed chemical firms to operate globally and made it easier to shift carbon-intense production to non-regulated regions. Similarly, some respondents from the chemical industry remarked in the open text fields that the regulatory uncertainty had caused the postponement of investments in carbon-intense business activities or, in one case, had even contributed to a demerger.

Surprisingly, potential regional differences in post-Kyoto regulation were only partly reflected in firms' strategic responses to the uncertainty associated with it. Rather, firms' responses are largely uniform across regions, except for a higher prevalence of adaptation strategies among firms in North America and a lower pursuit of reduction strategies among Asian firms. These results are consistent with empirical research on cultural variations in managing uncertainty, which finds that North American managers tend to pursue passive, risk-averse responses to uncertainty (Schneider and De Meyer 1991), while managers' tendency to reduce uncertainty seems to be lower in Japan than in Western cultures (Nonaka and Johansson 1985). On a similar note, our results corroborate findings that Asian managers are more likely to interpret strategic issues as threats than Western managers due to differences in national culture (Sallivan and Nonaka 1988; Schneider and De Meyer 1991). For example, the influence of regulatory rules and procedures on Asian firms has traditionally been stronger than on firms in Europe or North America, leading to high expectations of control from regulatory authorities (Smith et al. 1996). These expectations possibly exacerbate the perception of regulatory uncertainty as a threat. Accordingly, a Japanese respondent remarked in the open text field that "the number of legal restrictions imposed on us increases every year. [...] We need to know how to adequately deal with all these rules, otherwise we will not be able to continue our business." 
Besides cultural differences, varying uncertainty perceptions might also be influenced by differences in the current regulatory environment with respect to the reduction in $\mathrm{CO}_{2}$ emissions in Europe, North America, and Asia (Kolk and Hoffmann 2007). Interestingly, firms already familiar with the regulatory uncertainty associated with the reduction in $\mathrm{CO}_{2}$ emissions tend to adapt to such uncertainty in a post-Kyoto context to a greater extent than inexperienced firms. This could indicate that firms that already went through a period of regulatory uncertainty might try to take advantage of the groundwork laid during previous uncertainty response activities and attempt to continue adaptation measures initiated earlier. Respondents' explanations in the open text fields substantiate this notion, indicating that several utilities had initiated business portfolio reviews in response to the regulatory uncertainty prior to the implementation of the EU ETS and now took similar measures to adapt to the uncertainty regarding the successor scheme to the Kyoto Protocol. For example, many utilities attempted to further increase their flexibility by balancing their power plant portfolio across different energy sources such as coal, gas, and renewables.

Finally, firms with high $\mathrm{CO}_{2}$ emissions engage in activities to reduce and to avoid their regulatory uncertainty to a higher degree than firms with low $\mathrm{CO}_{2}$ emissions. This could be explained against the background of there being more at stake for the former, as in absolute terms they are likely to be more significantly affected by $\mathrm{CO}_{2}$ emission regulation than the latter. Thus, they possibly try harder to gather information or to withdraw from the area of application of the future regulation, at least temporarily until the degree of perceived regulatory uncertainty decreases. Indeed, respondents' comments repeatedly demonstrated a lack of both concern and interest in the regulatory issues examined in this study if the respective firm's $\mathrm{CO}_{2}$ emissions were low. For instance, one utility firm that generated a large share of its electricity in carbon-free hydroelectric power plants explained that "we do not see the need to respond to future uncertainties regarding a $\mathrm{CO}_{2}$ emission regulation."

\section{Implications}

Our findings can help policymakers to better predict the behavior of firms in different industries during policymaking, thereby enhancing the efficiency of this process and facilitating the design of an effective post-Kyoto regulation. First, firms that perceived a high degree of uncertainty associated with a $\mathrm{CO}_{2}$ emission regulation generally invested in activities to cope with this uncertainty instead of more effectively directing their efforts toward their commercial, but also environmental, objectives, for example by investing in activities to reduce emissions instead. Accordingly, regulatory uncertainty could have an unfavorable effect on firms' activities to reduce $\mathrm{CO}_{2}$ emissions and thus potentially counteract the regulation's objective. This especially applies to firms predominantly pursuing particularly resource-intense response strategies like adaptation, and to firms mostly pursuing reduction strategies that require the deployment of resources but do not yield additional business-related benefits. In these cases, policymakers should attempt to keep regulatory uncertainty low, for example by regularly communicating the status quo of the policymaking process and disclosing finalized and open issues, thereby encouraging firms to comply with future requirements in advance. Furthermore, they should attempt to keep the period during which firms are exposed to regulatory uncertainty short. This could be realized by extending the timeframe of existing regulations and by setting clear and reliable long-term targets, instead of frequently entering political debates to renegotiate and adjust short-term targets.

Secondly, the perception of the regulatory uncertainty as a threat also led firms to engage in countermeasures. In consequence, policymakers should attempt to enhance 
firms' perception of the controllability of uncertainty associated with a regulation in order to facilitate firms' more target-oriented resource deployment. Firms seek control over regulatory uncertainty mainly through contributing to the policymaking process, either directly or indirectly via industry and trade associations (Henisz and Delios 2004b). The consideration of such external contributions to environmental policymaking simplifies the implementation and enactment of a regulation and enhances compliance among firms (Bryner 2001; Burby and Paterson 1993; Yap 2003). Furthermore, increasing the transparency of political decision making for firms also reduces the regulatory uncertainty they are exposed to (Van den Hove 2000), thereby attenuating a firm's need to adapt to this uncertainty and its tendency to avoid it. Accordingly, policymakers should improve the mechanisms by which firms participate in the discussion of an issue to be regulated to increase both the efficiency of the policymaking process and the effectiveness of the regulation. However, as exemplified by the sharp contrast, according to our findings, between firms' public assertions to realize avoidance strategies and their low pursuit of them in reality, policymakers need to remain independent and to refrain from adopting firms' perspectives without further reflection. To this end, systematically also involving other stakeholders, such as scientists and NGOs, could help policymakers to balance economic goals with regulatory objectives and the public interest.

\section{Directions for future research}

We advocate studies that build on our findings and that examine effects of regulatory uncertainty on the timing of firms' influencing strategies to enhance the understanding of the interaction between policymakers and firms. In order to analyze the effectiveness of the four response strategies in overcoming constraints from regulatory uncertainty, we also suggest that scholars investigate the effect of pursuing these strategies on firm performance. Furthermore, future research should explore the rationale for firms' response choice in more detail. In line with previous research calling for a better understanding of the relationship between strategy and capabilities (DeSarbo et al. 2005; Hambrick 1983), we especially encourage studies focusing on the role of organizational capabilities for choosing and enacting a specific response strategy to regulatory uncertainty. Finally, in order to complement the research at hand, we believe that it is important to study the effects of the uncertainty associated with a $\mathrm{CO}_{2}$ emission regulation on firms' environmental strategy and most particularly on their activities to actually reduce $\mathrm{CO}_{2}$ emissions, especially in the context of the differences of existing regulatory schemes in different countries.

Acknowledgments This research was funded by the ClimPol project within the Competence Center for Environment \& Sustainability of the Swiss Federal Institute of Technology, whose support we gratefully acknowledge.

\section{Appendix}

Survey questions (Text in italics for explanation only, not included in questionnaire)

\section{Corporate strategies to respond to regulatory uncertainty (All items had five-point response formats)}

Please indicate which activities your company currently pursues to deal with the uncertainty related to a possible regulation to reduce the $\mathrm{CO}_{2}$ emissions of your company after 2012 and rate the respective extent of the pursued activities. 
Avoidance strategy $(\alpha=.63)$

1. We postpone our strategic decisions until we have more certainty. [Postponement]

2. We create predictability, e.g., by negotiating contracts or long-term rules with other companies or the government. [Stabilization]

3. We shift our business to markets probably not affected by a regulation. [Withdrawal] Reduction strategy $(\alpha=.66)$

1. We systematically search for additional information. [Investigation]

2. We engage in the policy-making process to contribute to the decision making. [Influencing]

3. We select specific issues in our business environment to focus on in order to simplify decision making. [Simplification]

Adaptation strategy $(\alpha=.76)$

1. We change our organizational structure, e.g., by increasing decentralization or lowering the degree of formalization, to better deal with the uncertainty. [Internal design]

2. We rearrange our portfolio through mergers, acquisitions, or divestures to be less exposed to regulatory uncertainty. [Integration]

3. We prepare for more than one potential outcome of the policy-making process. [Flexibility]

4. We join forces with others, e.g., suppliers, customers, or competitors. [Cooperation]

5. We observe the activities of other companies and follow them if appropriate. [Imitation]

Disregard strategy $(\alpha=.71)$

1. We agree on the regulation scenario we consider the most likely and focus on preparing for this scenario. [Substitution]

2. We only make investments which have a guaranteed positive return regardless of the outcome of a possible future regulation. [No-regret moves]

Perceived regulatory uncertainty (All items had five-point response formats) $(\alpha=.80)$

Please indicate how certain your company is about the following features of a possible regulation to reduce the $\mathrm{CO}_{2}$ emissions of your company after 2012 .

1. The existence of a $\mathrm{CO}_{2}$ emission reduction regulation for your company after 2012 .

2. The design details of a $\mathrm{CO}_{2}$ emission reduction regulation for your company after 2012.

3. The impact a $\mathrm{CO}_{2}$ emission reduction regulation on your company after 2012.

Perception of regulatory uncertainty as a threat (Respondents had to select one response option)

How does your company view the uncertainty related to a possible regulation to reduce the $\mathrm{CO}_{2}$ emissions of your company after 2012 ?

The regulatory uncertainty poses a threat for our company's entire operations.

The regulatory uncertainty poses a threat for major parts of our company's operations.

The regulatory uncertainty poses a threat for some parts of our company's operations.

The regulatory uncertainty does not pose a threat for our company's operations. 


\section{$\mathrm{CO}_{2}$ emissions}

Please indicate your company's total direct GHG emissions (metric tonnes $\mathrm{CO}_{2}$ equivalent) in the calendar year 2006.

Table 5 Results of Harman one-factor analysis (Extraction method: Principal component analysis)

\begin{tabular}{|c|c|c|c|c|c|c|}
\hline \multirow[t]{2}{*}{ Measure } & \multicolumn{6}{|c|}{ Component } \\
\hline & 1 & 2 & 3 & 4 & 5 & 6 \\
\hline Imitation & .590 & -.043 & -.038 & .004 & .124 & -.543 \\
\hline Flexibility & .585 & .029 & -.407 & .027 & .151 & .172 \\
\hline Substitution & .582 & .122 & -.057 & -.239 & .447 & .110 \\
\hline Stabilization & .552 & .127 & -.273 & -.203 & .193 & .306 \\
\hline Internal design & .529 & -.477 & .298 & .218 & -.021 & -.268 \\
\hline Postponement & .520 & -.353 & .374 & -.255 & .023 & .237 \\
\hline Investigation & .505 & .019 & -.485 & .332 & -.207 & -.122 \\
\hline Cooperation & .486 & .182 & -.363 & -.014 & -.041 & -.443 \\
\hline Integration & .468 & -.488 & .166 & -.292 & -.155 & -.092 \\
\hline Influencing & .452 & .016 & -.536 & .049 & -.316 & .281 \\
\hline No-regret moves & .444 & -.146 & .021 & .245 & -.124 & .277 \\
\hline Withdrawal & .389 & -.497 & .261 & .210 & -.389 & .157 \\
\hline Uncertainty-Existence of emission regulation & .542 & .538 & .390 & -.038 & -.020 & .020 \\
\hline Uncertainty-Regulation design details & .489 & .636 & .389 & .004 & -.099 & .043 \\
\hline Uncertainty-Regulatory impact on company & .311 & .587 & .349 & .112 & -.282 & -.032 \\
\hline Perception of regulatory uncertainty as a threat & -.017 & .027 & .143 & .791 & .406 & .129 \\
\hline Simplification & .375 & -.268 & .161 & .028 & .456 & -.018 \\
\hline
\end{tabular}

Table 6 Total variance explained (Extraction method: Principal component analysis)

\begin{tabular}{llcl}
\hline \multirow{2}{*}{ Component } & \multicolumn{3}{l}{ Extraction sums of squared loadings } \\
\cline { 2 - 4 } & Total & \% of variance & Cumulative \% \\
\hline 1 & 3.930 & 20.685 & 20.685 \\
2 & 2.052 & 10.798 & 31.483 \\
3 & 1.916 & 10.084 & 41.567 \\
4 & 1.262 & 6.640 & 48.207 \\
5 & 1.127 & 5.933 & 54.140 \\
6 & 1.045 & 5.502 & 59.642 \\
\hline
\end{tabular}

\section{References}

Amram, M., \& Kulatilaka, N. (1999). Uncertainty: The new rules for strategy. Journal of Business Strategy, 20(3), 25-29.

Anderson, C. R., \& Paine, F. T. (1975). Managerial perceptions and strategic behavior. Academy of Management Journal, 18(4), 811-823.

Anderson, P., \& Tushman, M. L. (2001). Organizational environments and industry exit: The effects of uncertainty, munificence and complexity. Industrial and Corporate Change, 10(3), 675-711. 
Andrews, R. N. L. (1998). Environmental regulation and business 'self-regulation'. Policy Sciences, 31(3), $177-197$.

Anger, N. (2008). Emissions trading beyond Europe: Linking schemes in a post-Kyoto world. Energy Economics, 30(4), 2028-2049.

Aragón-Correa, J. A., \& Sharma, S. (2003). A contingent resource-based view of proactive corporate environmental strategy. Academy of Management Review, 28(1), 71-88.

Arentsen, M. J., Bressers, H. T. A., \& O’Toole, L. J. (2000). Institutional and policy responses to uncertainty in environmental policy: A comparison of Dutch and U.S. styles. Policy Studies Journal, 28(3), 597611.

Argote, L., Turner, M. E., \& Fichman, M. (1989). To centralize or not to centralize: The effects of uncertainty and threat on group structure and performance. Organizational Behavior and Human Decision Processes, 43(1), 58-74.

Barr, P. S., \& Glynn, M. A. (2004). Cultural variations in strategic issue interpretation: Relating cultural uncertainty avoidance to controllability in discriminating threat and opportunity. Strategic Management Journal, 25(1), 59-67.

Bergh, D. D., \& Lawless, M. W. (1998). Portfolio restructuring and limits to hierarchical governance: The effects of environmental uncertainty and diversification strategy. Organization Science, 9(1), 87-102.

Bergkvist, L., \& Rossiter, J. R. (2007). The predictive validity of multiple-item versus single-item measures of the same constructs. Journal of Marketing Research, 44(2), 175-184.

Birnbaum, P. H. (1984). The choice of strategic alternatives under increasing regulation in high technology companies. Academy of Management Journal, 27(3), 489-510.

Blandin, J. S., Brown, W. B., \& Koch, J. L. (1977). Uncertainty and information-gathering behavior: An empirical investigation. Seattle: National Academy of Management Meeting.

Bourgeois, L. J. (1980). Strategy and environment: A conceptual integration. Academy of Management Review, 5(1), 25-39.

Bourgeois, L. J. (1985). Strategic goals, perceived uncertainty, and economic performance in volatile environments. Academy of Management Journal, 28(3), 548-573.

Bourgeois, L. J., \& Eisenhardt, K. M. (1987). Strategic decision processes in Silicon Valley: The anatomy of a "living dead". California Management Review, 30(1), 143-159.

Bourgeois, L. J., \& Eisenhardt, K. M. (1988). Strategic decision processes in high velocity environments: Four cases in the microcomputer industry. Management Science, 34(7), 816-835.

Boynton, A. C., Gales, L. M., \& Blackburn, R. S. (1993). Managerial search activity: The impact of perceived role uncertainty and role threat. Journal of Management, 19(4), 725-747.

Brewer, T. L. (2005). Business perspectives on the EU emissions trading scheme. Climate Policy, 5(1), 137144.

Bryner, G. (2001). Cooperative instruments and policy making: Assessing public participation in US environmental regulation. European Environment, 11(1), 49-60.

Burby, R. J., \& Paterson, R. G. (1993). Improving compliance with state environmental regulations. Journal of Policy Analysis and Management, 12(4), 753-772.

Burns, T., \& Stalker, G. M. (1961). The management of innovation. New York: Oxford University Press.

Burtraw, D., \& Palmer, K. (2008). Compensation rules for climate policy in the electricity sector. Journal of Policy Analysis and Management, 27(4), 819-847.

Carter, N. M. (1990). Small firm adaptation: Responses of physicians' organizations to regulatory and competitive uncertainty. Academy of Management Journal, 33(2), 307-333.

Chattopadhyay, P., Glick, W. H., \& Huber, G. P. (2001). Organizational actions in response to threats and opportunities. Academy of Management Journal, 44(5), 937-955.

Christmann, P., \& Taylor, G. (2001). Globalization and the environment: Determinants of firm self-regulation in China. Journal of International Business Studies, 32(3), 439-458.

Collis, D. (1992). The strategic management of uncertainty. European Management Journal, 10(2), 125135.

Courtney, H., Kirkland, J., \& Viguerie, P. (1997). Strategy under uncertainty. Harvard Business Review, 75(6), 67-79.

Crew, M. A. (1982). Efficiency and regulation: A basis for reform. Managerial and Decision Economics, 3(4), 117-187.

Cyert, R. M., \& March, J. G. (1963). A behavioral theory of the firm. Englewood Cliffs, NJ: Prentice-Hall.

D'Aveni, R. A., \& MacMillan, I. C. (1990). Crisis and the content of managerial communications: A study of the focus of attention of top managers in surviving and failing firms. Administrative Science Quarterly, 35(4), 634-657.

Daft, R. L., \& Weick, K. E. (1984). Toward a model of organizations as interpretation systems. Academy of Management Review, 9(2), 284-295. 
Darnall, N., \& Carmin, J. (2005). Greener and cleaner? The signaling accuracy of U.S. voluntary environmental programs. Policy Sciences, 38(2/3), 71-90.

Delmas, M., \& Tokat, Y. (2005). Deregulation, governance structures, and efficiency: The U.S. electric utility sector. Strategic Management Journal, 26(5), 441-460.

DeSarbo, W. S., Di Benedetto, C. A., Song, M., \& Sinha, I. (2005). Revisiting the Miles and Snow strategic framework: Uncovering interrelationships between strategic types, capabilities, environmental uncertainty, and firm performance. Strategic Management Journal, 26(1), 47-74.

Dixit, A. (1989). Entry and exit decisions under uncertainty. The Journal of Political Economy, 97(3), 620638.

Dixit, A., \& Pindyck, R. (1994). Investment under uncertainty. Princeton, NJ: Princeton University Press.

Doh, J. P., \& Pearce, J. A. (2004). Corporate entrepreneurship and real options in transitional policy environments: Theory development. Journal of Management Studies, 41(4), 645-664.

Downey, H. K., Hellriegel, D., \& Slocum, J. W. (1977). Individual characteristics as sources of perceived uncertainty variability. Human Relations, 30(2), 161-174.

Dreyer, B., \& Grønhaug, K. (2004). Uncertainty, flexibility, and sustained competitive advantage. Journal of Business Research, 57(5), 484-494.

Dutton, J. E., \& Duncan, R. B. (1987). The creation of momentum for change through the process of strategic issue diagnosis. Strategic Management Journal, 8(3), 279-295.

Dutton, J. E., \& Jackson, S. E. (1987). Categorizing strategic issues: Links to organizational action. Academy of Management Review, 12(1), 76-90.

Dutton, J. E., Stumpf, S. A., \& Wagner, D. (1990). Diagnosing strategic issues and managerial investment of resources. In P. Shrivastava \& R. B. Lamb (Eds.), Advances in strategic management. Greenwich, CT: JAI Press.

Elenkov, D. S. (1997). Strategic uncertainty and environmental scanning: The case for institutional influences on scanning behavior. Strategic Management Journal, 18(4), 287-302.

Emery, F. E. (1967). The next thirty years: Concepts, methods and anticipations. Human Relations, 20(3), 199-237.

Engau, C., \& Hoffmann, V. H. (2009). Effects of regulatory uncertainty on corporate strategy - an analysis of firms' responses to uncertainty about post-Kyoto policy. Environmental Science \& Policy, 12(7), $766-777$.

Faucheux, S., \& Froger, G. (1995). Decision-making under environmental uncertainty. Ecological Economics, 15(1), 29-42.

Fowler, F. J. (1993). Survey research methods. Newbury Park, CA: Sage.

Galbraith, J. R. (1973). Designing complex organizations. Reading, MA: Addison-Wesley.

Grubb, M., Vrolijk, C., \& Brack, D. (1999). The Kyoto protocol-a guide and assessment. London: RIIA.

Hair, J. F., Anderson, R. E., Tatham, R. L., \& Black, W. C. (1998). Multivariate data analysis. Englewood Cliffs, NJ: Prentice-Hall.

Hambrick, D. C. (1981). Environment, strategy, and power within top management teams. Administrative Science Quarterly, 26(2), 253-275.

Hambrick, D. C. (1983). Some tests of the effectiveness and functional attributes of Miles and Snow's strategic types. Academy of Management Journal, 26(1), 5-26.

Harrison, K. (2007). The road not taken: Climate change policy in Canada and the United States. Global Environmental Politics, 7(4), 92-117.

Henisz, W. J., \& Delios, A. (2001). Uncertainty, imitation, and plant location: Japanese multinational corporations, 1990-1996. Administrative Science Quarterly, 46(3), 443-475.

Henisz, W. J., \& Delios, A. (2004a). Information or influence? The benefits of experience for managing political uncertainty. Strategic Organization, 2(4), 389-421.

Henisz, W. J., \& Delios, A. (2004b). Following the herd and sleeping with the enemy: Strategies for managing policy uncertainty, Academy of Management Proceedings, M1-M6.

Hickson, D. J., Hinings, C. R., Lee, C. A., Schneck, R. E., \& Pennings, J. M. (1971). A strategic contingencies' theory of intraorganizational power. Administrative Science Quarterly, 16(2), 216-229.

Hillman, A. J., \& Hitt, M. A. (1999). Corporate political strategy formulation: A model of approach, participation, and strategy decisions. Academy of Management Review, 24(4), 825-842.

Hoffmann, V. H. (2007). EU ETS and investment decisions: The case of the German electricity industry. European Management Journal, 25(6), 464-474.

Hoffmann, V. H., \& Trautmann, T. (2006). The role of industry and uncertainty in regulatory pressure and environmental strategy, Academy of Management Best Conference Paper 2006 ONE, D1-D6.

Hoffmann, V. H., Trautmann, T., \& Hamprecht, J. (2009). Regulatory uncertainty-a reason to postpone investments? Not necessarily. Journal of Management Studies, 46(7), 1227-1253. 
Hoffmann, V. H., Trautmann, T., \& Schneider, M. (2008). A taxonomy for regulatory uncertainty-application to the European emission trading scheme. Environmental Science \& Policy, 11(8), 712-722.

Hofstede, G. H. (1980). Cultures consequences. Beverly Hills, CA: Sage.

Hrebiniak, L. G., \& Snow, C. C. (1980). Research notes: Industry differences in environmental uncertainty and organizational characteristics related to uncertainty. Academy of Management Journal, 23(4), 750759.

Ireland, R. D., Hitt, M. A., Bettis, R. A., \& de Porras, D. A. (1987). Strategy formulation processes: Differences in perceptions of strength and weaknesses indicators and environmental uncertainty by managerial level. Strategic Management Journal, 8(5), 469-485.

Jackson, S. E., \& Dutton, J. E. (1988). Discerning threats and opportunities. Administrative Science Quarterly, 33(3), 370-387.

Jackson, S. E., Schuler, R. S., \& Vredenburgh, D. J. (1987). Managing stress in turbulent times. In A. W. Riley \& S. J. Zaccaro (Eds.), Occupational stress and organizational effectiveness. New York: Praeger.

Jauch, L. R., Osborn, R. N., \& Glueck, W. F. (1980). Short term financial success in large business organizations: The environment-strategy connection. Strategic Management Journal, 1(1), 49-63.

Keeler, A. G. (2007). State greenhouse gas reduction policies: A move in the right direction? Policy Sciences, 40(4), 353-365.

Khandwalla, P. N. (1978). Crisis responses of competing versus noncompeting organizations. In C. Smart \& W. Stanbury (Eds.), Studies on crisis management. Toronto: Institute for Research on Public Policy.

Klassen, R. D., \& Angell, L. C. (1998). An international comparison of environmental management in operations: The impact of manufacturing flexibility in the U.S. and Germany. Journal of Operations Management, 16(2/3), 177-194.

Koberg, C. S. (1987). Resource scarcity, environmental uncertainty, and adaptive organizational behavior. Academy of Management Journal, 30(4), 798-807.

Kolk, A., \& Hoffmann, V. (2007). Business, climate change and emissions trading: Taking stock and looking ahead. European Management Journal, 25(6), 411-414.

Kolk, A., \& Pinkse, J. (2005). Business responses to climate change: Identifying emergent strategies. California Management Review, 47(3), 6-20.

Krickx, G. A. (2000). The relationship between uncertainty and vertical integration. International Journal of Organizational Analysis, 8(3), 309-329.

Lave, L. B. (1988). The greenhouse effect: What government actions are needed? Journal of Policy Analysis and Management, 7(3), 460-470.

Lawrence, P. R., \& Lorsch, J. W. (1967). Differentiation and integration in complex organizations. Administrative Science Quarterly, 12(1), 1-47.

Lev, B. (1975). Environmental uncertainty reduction by smoothing and buffering: An empirical verification. Academy of Management Journal, 18(4), 864-871.

Levinthal, D. A., \& March, J. G. (1993). The myopia of learning. Strategic Management Journal, 14(8), 95112.

Levy, D. L. (1997). Business and international environmental treaties: Ozone depletion and climate change. California Management Review, 39(3), 54-71.

Litschert, R. J., \& Bonham, T. W. (1979). Strategic responses to different perceived strategic challenges. Journal of Management, 5(1), 91-105.

Majumdar, S. K., \& Marcus, A. A. (2001). Rules versus discretion: The productivity consequences of flexible regulation. Academy of Management Journal, 44(1), 170-179.

March, J. G., \& Simon, H. A. (1958). Organizations. New York: Wiley.

Marcus, A. A. (1981). Policy uncertainty and technological innovation. Academy of Management Review, $6(3), 443-448$.

Marcus, A. A. (1987). U.S. firms' responses to regulation: Stonewalling and opportunism. Long Range Planning, 20(3), 98-104.

Marcus, A. A., \& Kaufman, A. M. (1986). Why it is so difficult to implement industrial policies: Lessons from the synfuels experience. California Management Review, 28(4), 98-114.

Mascarenhas, B. (1982). Coping with uncertainty in international business. Journal of International Business Studies, 13(2), 87-98.

McMullen, J. S., \& Shepherd, D. A. (2006). Entrepreneurial action and the role of uncertainty in the theory of the entrepreneur. Academy of Management Review, 31(1), 132-152.

McNeeley, B. J. (1995). The relationship of regulatory uncertainty and coalition formation within marketing channels. Journal of Marketing Management, 5(1), 47-61.

Miller, K. D. (1992). A framework for integrated risk management in international business. Journal of International Business Studies, 23(2), 311-331. 
Miller, K. D., \& Folta, T. B. (2002). Option value and entry timing. Strategic Management Journal, 23(7), $655-665$.

Miller, D., \& Friesen, P. H. (1983). Strategy-making and environment: The third link. Strategic Management Journal, 4(3), 221-235.

Miller, D., Kets de Vries, M. F. R., \& Toulouse, J.-M. (1982). Top executive locus of control and its relationship to strategy-making, structure, and environment. Academy of Management Journal, 25(2), 237-253.

Milliken, F. J. (1987). Three types of perceived uncertainty about environment: State, effect, and response uncertainty. Academy of Management Review, 12(1), 133-143.

Nonaka, I., \& Johansson, J. K. (1985). Japanese management: What about the "hard" skills? Academy of Management Review, 10(2), 181-191.

Nunnally, J. C. (1978). Psychometric theory. New York: McGraw-Hill.

Paulsson, F., \& von Malmborg, F. (2004). Carbon dioxide emission trading, or not? An institutional analysis of company behaviour in Sweden. Corporate Social Responsibility and Environmental Management, 11(4), 211-221.

Podsakoff, P. M., MacKenzie, S. B., Lee, J.-Y., \& Podsakoff, N. P. (2003). Common method biases in behavioral research: A critical review of the literature and recommended remedies. Journal of Applied Psychology, 88(5), 879-903.

Rivera, J., Oetzel, J., de Leon, P., \& Starik, M. (2009). Business responses to environmental and social protection policies: Toward a framework for analysis. Policy Sciences, 42(1), 3-32.

Rugman, A. M., \& Verbeke, A. (1998). Corporate strategies and environmental regulations: An organizing framework. Strategic Management Journal, 19(4), 363-375.

Rugman, A. M., \& Verbeke, A. (2001). Environmental policy and international business. In A. M. Rugman \& T. L. Brewer (Eds.), Oxford handbook of international business. New York: Oxford University Press.

Sallivan, J., \& Nonaka, I. (1988). Culture and strategic issue categorization theory. Management International Review, 28(3), 6-10.

Schneider, S. C., \& De Meyer, A. (1991). Interpreting and responding to strategic issues: The impact of national culture. Strategic Management Journal, 12(4), 307-320.

Sharma, S. (2000). Managerial interpretations and organizational context as predictors of corporate choice of environmental strategy. Academy of Management Journal, 43(4), 681-697.

Smart, C., \& Vertinsky, I. (1977). Designs for crisis decision units. Administrative Science Quarterly, 22(4), 640-657.

Smith, P. B., Peterson, M. F., \& Wang, Z. M. (1996). The manager as mediator of alternative meanings: A pilot study from China, the USA and UK. Journal of International Business Studies, 27(1), 115-137.

Staw, B. M., Sandelands, L. E., \& Dutton, J. E. (1981). Threat-rigidity effects in organizational behavior: A multilevel analysis. Administrative Science Quarterly, 26(4), 501-524.

Sullivan, R., \& Blyth, W. (2006). Climate change policy and the electricity industry: Implications and unintended consequences (pp. 1-11). London: The Royal Institute of International Affairs.

Tarui, N., \& Polasky, S. (2005). Environmental regulation with technology adoption, learning and strategic behavior. Journal of Environmental Economics and Management, 50(3), 447-467.

Thomas, J. B., Clark, S. M., \& Gioia, D. A. (1993). Strategic sensemaking and organizational performance: Linkages among scanning, interpretation, action, and outcomes. Academy of Management Journal, 36(2), 239-270.

Thomas, J. A., \& McDaniel, R. R. (1990). Interpreting strategic issues: Effects of strategy and the information-processing structure of top management teams. Academy of Management Journal, 33(2), 286306.

Thompson, J. D. (1967). Organizations in action. New York: McGraw-Hill.

Ullmann, A. A. (1985). The impact of the regulatory life cycle on corporate political strategy. California Management Review, 28(1), 140-154.

UNFCC (2007). Decision -/cp. 13: Bali action plan. Bali: United Nations.

Van den Hove, S. (2000). Participatory approaches to environmental policy-making: The European Commission climate policy process as a case study. Ecological Economics, 33(3), 457-472.

Venkatraman, N., \& Grant, J. H. (1986). Construct measurement in organizational strategy research: A critique and proposal. Academy of Management Review, 11(1), 71-87.

Weick, K. E. (1969). The social psychology of organizing. Reading, MA: Addison Wesley.

Weick, K. E. (1995). Sensemaking in organizations. Thousand Oaks, CA: Sage.

Wernerfelt, B., \& Karnani, A. (1987). Competitive strategy under uncertainty. Strategic Management Journal, 8(2), 187-194. 
Yamin, F. (1998). Climate change negotiations: An analysis of the Kyoto Protocol. International Journal of Environment and Pollution, 10(3/4), 428-453.

Yang, B., Burns, N. D., \& Backhouse, C. J. (2004). Management of uncertainty through postponement. International Journal of Production Research, 42(6), 1049-1064.

Yap, O. F. (2003). Government's credible commitment in economic policy-making: Evidence from Singapore. Policy Sciences, 36(3/4), 237-255.

Yarbrough, B. V., \& Yarbrough, R. M. (1990). International institutions and the new economics of organization. International Organization, 44(2), 235-259.

Yasai-Ardekani, M. (1986). Structural adaptations to environments. Academy of Management Review, 11(1), 9-21. 